\title{
Early respiratory evaluation should be carried out systematically in patients with multiple sclerosis
}

\author{
Avaliação respiratória precoce deveria ser feita sistematicamente em pacientes com \\ esclerose múltipla
}

Fernanda Machado Taveira1, Antônio Lúcio Teixeira², Renan Barros Domingues ${ }^{3}$

\begin{abstract}
The present study aimed at evaluating respiratory parameters in multiple sclerosis (MS). The sample comprised 30 patients with MS diagnosis and 30 healthy subjects, matched by gender and age. Neurological assessment, expanded disability status scale (EDSS), manovacuometry, and peak flow (PEF) were performed. Patients with MS had lower values of maximum inspiratory (MIP) and expiratory (MEP) pressures and PEF compared to healthy controls. It was shown that respiratory impairment may be present in MS patients with low functional disability by EDSS. The data suggest that manovacuometry and PEF determination should be carried out systematically in patients with MS, and may be a reliable tool for the early detection of respiratory impairment allowing early respiratory rehabilitation.
\end{abstract}

Key words: multiple sclerosis, respiratory function, respiratory function tests.

\section{RESUMO}

O presente estudo teve como objetivo avaliar a função respiratória em pacientes com esclerose múltipla (EM). A amostra foi composta por 30 pacientes com diagnóstico de EM e 30 sujeitos saudáveis, pareados de acordo com o gênero e a idade. Foram realizados avaliação neurológica, determinação da escala expandida do estado de incapacidade (EDSS), manovacuometria e "peak flow". Pacientes com EM apresentaram pressões inspiratória (PI) e expiratória (PE) máximas inferiores e menor PFE quando comparados aos controles saudáveis. Identificou-se que o comprometimento respiratório pode ocorrer em pacientes com EM, mesmo com baixo grau de comprometimento funcional estimado pelo EDSS. Os dados do presente estudo sugerem que a avaliação respiratória com manovacuometria e PFE deve ser realizada sistematicamente em pacientes com EM, e pode ser uma ferramenta útil para detectar precocemente comprometimento respiratório, podendo sugerir a necessidade de reabilitação pulmonar precoce em pacientes com EM.

Palavras-Chave: esclerose múltipla, função respiratória, testes de função respiratória.

Multiple sclerosis (MS) affects motor pathways and is associated with reduced muscle strength, including the respiratory muscles ${ }^{1-5}$. Respiratory complications are recognized as the leading causes of morbidity and mortality in patients with advanced $\mathrm{MS}^{3-4}$. Nearly half of the MS patients in advanced stages die as a consequence of respiratory complications, such as aspiration pneumonia, atelectasis, and respiratory failure ${ }^{2,4-6}$. The progression of respiratory dysfunction occurs as a result of the weakness and fatigue of respiratory muscles (inspiratory and expiratory) and failure to maintain the airways free of secretions ${ }^{7}$. Abnormalities were shown in both expiratory (abdominal muscles and internal intercostal) and inspiratory muscles (diaphragm and external intercostal) among MS patients ${ }^{2}$.

Some authors have suggested that the decrease in respiratory muscle strength in MS depends on the size and location of lesions in the central nervous system (CNS). Other factors may also determine respiratory involvement in MS, such as corticosteroids myopathy, inflammatory cytokines like tumor necrosis factor (TNF), spasticity, incoordination, and

\footnotetext{
1Physical therapist, Master's degree in Neurosciences, Federal University of Minas Gerais, Belo Horizonte MG, Brazil;

${ }^{2} \mathrm{MD}$, PhD, Professor of Neurology, Department of Internal Medicine, School of Medicine, and Neuroscience Postgraduation Program, Federal University of Minas Gerais, Belo Horizonte MG, Brazil;

${ }^{3} \mathrm{MD}$, PhD, Professor, Department of Pathology, Santa Casa School of Health Sciences, Vitória ES, Brazil and Neuroscience Postgraduation Program, Federal University of Minas Gerais, Belo Horizonte MG, Brazil.

Correspondence: Renan Barros Domingues; Rua Professor Almeida Cousin 125 / sala 1.310; 29050-565 Vitória ES - Brasil; E-mail: contato@renandomingues.med.br Conflict of interest: There is no conflict of interest to declare.
}

Received 13 August 2012; Received in final form 24 September 2012; Accepted 01 October 2012. 
postural changes ${ }^{2,3}$. However, there is still little evidence regarding this.

The present study aimed at evaluating respiratory function in a population of MS patients with conventional respiratory parameters, such as maximum inspiratory pressure (MIP), maximum expiratory pressure (MEP), and peak flow (PEF).

\section{METHODS}

The study was conducted in Multiple Sclerosis Clinic at Hospital da Santa Casa de Misericórdia de Vitória. Thirty MS patients diagnosed according to the international panel criteria by Polman et al. ${ }^{8}$ were included. The Control Group consisted of 30 healthy subjects matched by gender and age.

Patients with temporomandibular disorders (TMD), remissions, infections, and other neurological diseases potentially compromising respiratory capacity were not included.

All participants were submitted to complete neurologic examination and determination of Expanded Functional Disability Scale (EDSS). According to the EDSS score, patients were divided into two groups: EDSS bellow 4 and EDSS equal or above 4 . Measurement of MIP and MEP was performed with a manovacuometer (model M120; Commercial Medicine, São Paulo, Brazil), and measurement of peak expiratory flow (PEF) was performed with "peak flow" (Model Asses, full range 60-880 L/min; Respironics New Jersey, Inc., USA). Müller maneuver was used for MIP measurement ${ }^{9}$, and the Valsalva one was used for $\mathrm{MEP}^{9}$. PEF measurement was carried out as previously described ${ }^{10}$.

\section{Statistical analysis}

Data were analyzed with the GraphPad Prism version 5.0 and $\mathrm{R}$ statistical software version 2.14.1. The confidence interval was of $95 \%$ and the significance level was set as $\mathrm{p}<0.05$.

Verification of data normal distribution was performed using the Kolmogorov-Smirnov test. To compare medians between MS patients and controls, we used the nonparametric MannWhitney's test. Median MIP, MEP, and PEF of patients with EDSS bellow 4 were compared with those of controls. The same procedure was conducted with patients with EDSS equal or above 4.

\section{RESULTS}

Of the 30 patients analyzed, 26 (86.67\%) were female and 4 (13.33\%) were male. The mean age was $36.66 \pm 11.78$ years-old. The mean EDSS was 2.63 \pm 1.65 . MS forms were: relapsing-remitting including 26 (86.66\%); secondary progressive, 3 (10.0\%); and primary progressive, 1 (3.33\%).

Two patients $(6.66 \%)$ were not using immunomodulators or immunosuppressants. Among the 28 patients receiving specific MS drugs, $46.42 \%$ were using beta-interferon $1 \mathrm{~A} 44 \mu \mathrm{cg}$, $14.28 \%$ glatiramer acetate, $14.28 \%$ beta-interferon 1 A $30 \mu \mathrm{cg}$,
$10.71 \%$ beta-interferon 1B SC 9600000UI, 3.57\% azathioprine, and $3.57 \%$ beta-interferon $1 \mathrm{~A} 22 \mu \mathrm{cg}$.

The MIP of patients was $81.4 \pm 30.91 \mathrm{cmH}_{2} \mathrm{O}$ and of controls $103.93 \pm 18.63 \mathrm{cmH}_{2} \mathrm{O}(\mathrm{p}=0.0092)$, as in Fig 1. The MEP measured in patients was $85.4 \pm 21.23 \mathrm{~cm} \mathrm{H}_{2} \mathrm{O}$ and $100.66 \pm 15 \mathrm{cmH}_{2} \mathrm{O}$ in the Control Group ( $\mathrm{p}=0.0034)$, as seen in Fig 2. The PEF ofMS patients was $370.16 \pm 92.11 \mathrm{~L} / \mathrm{min}$. and of controls was $436.5 \pm 79.51 \mathrm{~L} / \mathrm{min}$. ( $\mathrm{p}=0.0051)$, as in Fig 3.

The comparisons of median MIP, MEP, and PEF of both groups according to the EDSS and controls are shown in Table.

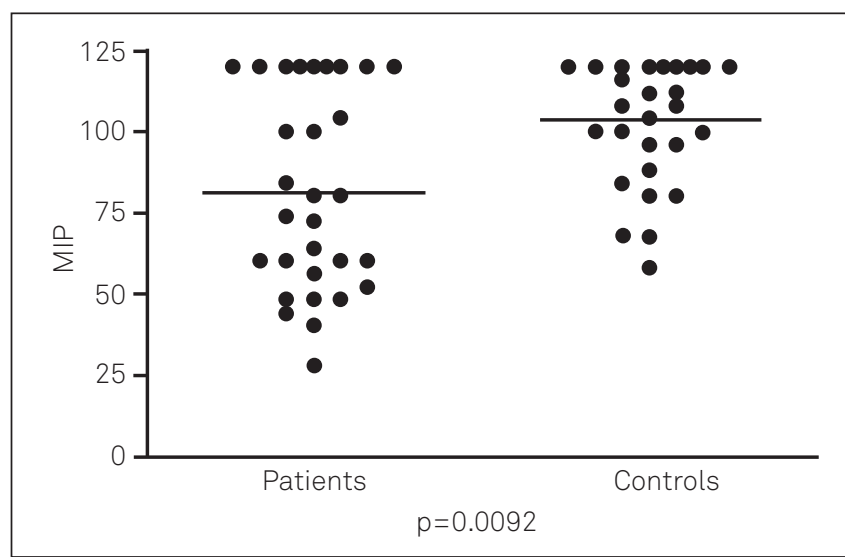

Fig 1. Maximum inspiratory pressure (MIP) in patients and controls.

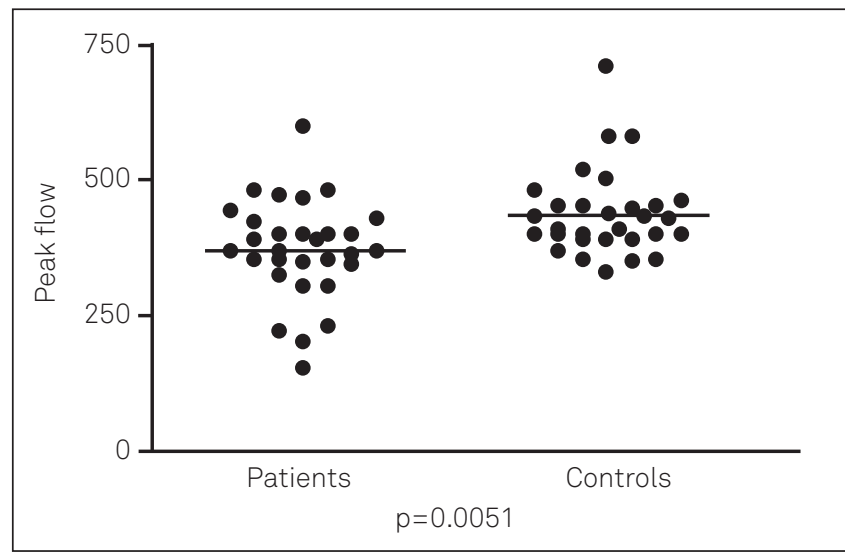

Fig 2. Maximum expiratory pressure (MEP) in patients and controls.

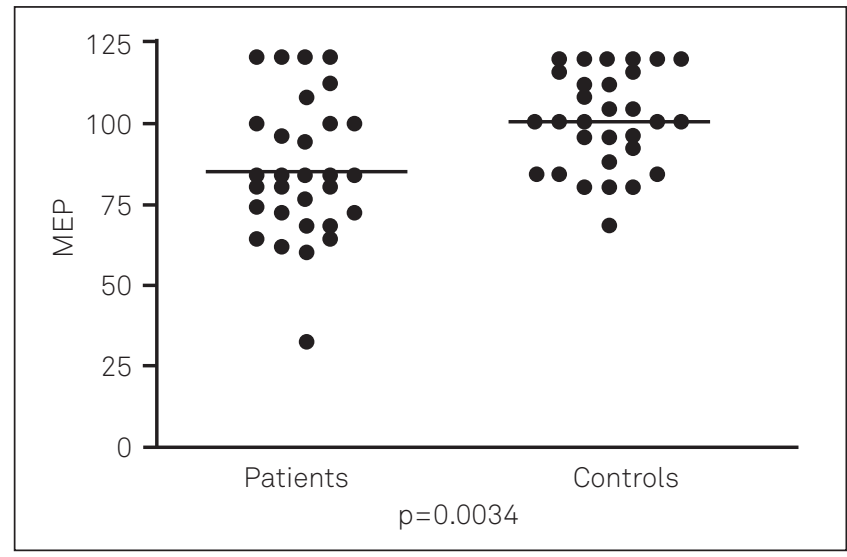

Fig 3. Peak flow in patients and controls. 
Table. Comparison of median maximum inspiratory and expiratory pressures, and peak flow between controls and patients, according to the expanded disability status scale.

\begin{tabular}{|c|c|c|c|c|c|}
\hline & $\begin{array}{c}\text { Controls }(n=25) \\
\text { Median }(\min -\max )\end{array}$ & $\begin{array}{c}\text { EDSS }<4(n=20) \\
\text { Median }(\min -\max )\end{array}$ & $p$-value & $\begin{array}{c}\text { EDSS } \geq 4(n=5) \\
\text { Median (min-max) }\end{array}$ & $\mathrm{p}$-value \\
\hline $\begin{array}{l}\mathrm{MIP} \\
\left(\mathrm{cmH}_{2} \mathrm{O}\right)\end{array}$ & $\begin{array}{c}86 \\
(28-120) \\
\end{array}$ & $\begin{array}{c}80 \\
(28-120)\end{array}$ & 0.62 & $\begin{array}{c}60 \\
(48-120)\end{array}$ & 0.86 \\
\hline $\begin{array}{l}\text { MEP } \\
\left(\mathrm{cmH}_{2} \mathrm{O}\right)\end{array}$ & $\begin{array}{c}100 \\
(68-120)\end{array}$ & $\begin{array}{c}84 \\
(32-120)\end{array}$ & 0.0087 & $\begin{array}{c}80 \\
(60-100)\end{array}$ & 0.045 \\
\hline $\begin{array}{l}\text { PFE } \\
\left(\mathrm{cmH}_{2} \mathrm{O}\right)\end{array}$ & $\begin{array}{c}420 \\
(330-710)\end{array}$ & $\begin{array}{c}370 \\
(150-600)\end{array}$ & 0.0179 & $\begin{array}{c}370 \\
(200-400)\end{array}$ & 0.0208 \\
\hline
\end{tabular}

MIP: maximum inspiratory pressure; MEP: maximum expiratory pressure; PFE: peak flow; EDSS: expanded disability status scale.

\section{DISCUSSION}

The present study showed a reduction in respiratory function parameters in MS patients compared to healthy controls. Compromising of respiratory function is well-known in patients with advanced MS. In our study, most patients had minimal disability and low EDSS score suggesting that respiratory dysfunction can be identified even in patients with minimal to moderate disability. Few previous studies have already showed that respiratory muscle strength and functional capacity may be early affected in MS patients ${ }^{11,12}$.

MIP was significantly lower in MS patients. This finding is in line with previous studies showing reduced levels of inspiratory pressure in $\mathrm{MS}^{1,3,5,13-19}$. The same occurred with MEP, and lower expiratory pressure was already shown in $\mathrm{MS}^{1,3,4,5,13-19}$. It was not possible to assess which of these two pressures is affected earlier in the course of MS, since this was a cross-sectional study.

PEF rate was significantly lower in MS patients. Only few studies have addressed it in MS, but in most of them a decrease in PEF in patients with MS was shown, such as in Savci et al.', Buyse et al. ${ }^{15}$, and Chiara et al. ${ }^{19}$. PEF is an easy-to-perform and inexpensive method, and the present study showed that it is potentially useful in evaluating respiratory function in patients with MS.

When we subdivided patients according to the EDSS and compared with controls, differences were found in MEP and PFE between patients and controls, regardless the EDSS being lower than four or above. This reinforces the notion that respiratory dysfunction may be found in fully deambulatory MS patients with low functional disability. There were no differences of the MIP between patients and controls when we analyzed the two subgroups of patients according to the EDSS. This may have happened because the number of patients in the subgroups was low, not allowing a significant difference to appear.

The present study has clear limitations. No correlations were performed with the type of therapy used by the patient. However, patients during relapses or infections were excluded.

It is unknown if immunomodulatory and immunosuppressive therapies potentially affect respiratory function in MS.

Correlations between respiratory impairment and lesions of the cervical spinal cord and brainstem were not investigated. It is possible that lesions in these CNS regions may be part of the respiratory impairment pathophysiology.

Patients with all forms of the disease were enrolled. Those with the progressive forms of MS were not excluded, but the number of subjects with secondary or primary progressive forms was very small and had probably little influence in the final results. In addition, respiratory dysfunction was found in patients with minimal to moderate disability.

Previous studies showed that ${ }^{3,5,18,19}$ breathing exercises may reduce the risk of respiratory complications and that early detection of decreased respiratory muscle strength is very important in this preventive process.

Further studies are needed in order to clarify the relationship between lesions of the cervical spinal cord and brainstem respiratory symptoms in patients with MS and to examine separately the respiratory impairment in patients with different forms of the disease and stages of evolution.

A systematic and simple evaluation of respiratory parameters can be useful for the detection of early reduction in respiratory muscle strength, thus possibly allowing to establish an evaluation of early respiratory rehabilitation programs in patients with MS.

\section{References}

1. Savci S, Inal-Ince D, Arikan $\mathrm{H}$, et al. Six-minute walk distance as a mesure of functional exercise capacity in multiple sclerosis. Disabil Rehabil 2005;27:1365-171.

2. Grosselink R, Kovacs L, Decramer M. Respiratory muscle involvement in multiple sclerosis. Eur Respir J 1999;13:449-454.

3. Fry DK, Pfalzer LA, Chokshi AR, et al. Randomized control trial of effects of a 10-week inspiratory muscle training program on measures of pulmonary function in persons with multiple sclerosis. $J$ Neurol Phys Ther 2007;31:162-172.
4. Aiello M, Rampello A, Granella F, et al. Cough efficacy is related to the disability status in patients with multiple sclerosis. Respiration 2008;76:311-316.

5. Grosselink R, Kovacs L, Ketelaer P, et al. Respiratory muscle weakness and respiratory muscle training in severely disabled multiple sclerosis patients. Arch Phys Med Rehabil 2000;81:747-751.

6. Mutluay FK, Demir R, Ozyilmaz S, et al. Breathing-enhanced upper extremity exercises for patients with multiple sclerosis. Clin Rehabil 2007;21:595-602. 
Paschoal IA, Villalba WO, Pereira MC. Insuficiência respiratória crônica nas doenças neuromusculares: diagnóstico e tratamento. J Bras Pneumol 2007;33:81-92.

8. Polman $\mathrm{CH}$, Reingold SC, Banwell B, et al. Diagnostic criteria for multiple sclerosis: 2010 Revisions to the McDonald Criteria. Ann Neurol 2011;69:292-302.

9. Souza RB. Pressões respiratórias estáticas máximas. J Pneumol 2002;28:155-164.

10. Nunn AJ, Gregg I. New regression equations for predicting peak expiratory flow in adults. Br Med J 1989;298:1068-1072.

11. Motl RW, Goldman MD, Benedict RH. Walking impairment in patients with multiple sclerosis: exercise training as a treatment option. Neuropsychiatr Dis Treat 2010;16:767-774.

12. Bosnak-Guclu M, Guclu-Gunduz A, Nazliel B, et al. Comparison of functional exercise capacity, pulmonary function and respiratory muscle strength in patients with multiple sclerosis with different disability levels and healthy controls. J Rehabil Med 2012;44:80-86.
13. Altintas A, Demir T, Ikitimur HD, et al. Pulmonary function in multiple sclerosis without any respiratory complaints. Clin Neurol Neurosurg 2007;109:242-246.

14. Smeltzer SC, Skurnick JH, Troiano R, et al. Respiratory function in multiple sclerosis. Utility of clinical assessment of respiratory muscle function. Chest 1992;101:479-484.

15. Buyse B, Demedts M, Meekers J, et al. Respiratory dysfunction in multiple sclerosis: a prospective analysis of 60 patients. Eur Respir J 1997;10:139-145.

16. Mutluay FK, Gürses HN, Saip S. Effects of multiple sclerosis on respiratory functions. Clin Rehabil 2005;19:426-432.

17. Foglio K, Clini E, Facchetti D, et al. Respiratory muscle function and exercise capacity in Multiple Sclerosis. Eur Respir J 1994;7:23-28.

18. Klefbeck B, Nedjad JH. Effect of inspiratory muscle training in patients with multiple sclerosis. Arch Phys Med Rehabil 2003;84:994-999.

19. Chiara T, Martin AD, Davenport PW, et al. Expiratory muscle strength training in persons with multiple sclerosis having mild to moderate disability: effect on maximal expiratory pressure, pulmonary function, and maximal voluntary cough. Arch Phys Med Rehabil 2006;87:468-743. 